\title{
Monitoring of uncultured Dunaliella sp. in an Egyptian solar saltern field based on RuBisCO-encoding gene $c b b L$
}

\author{
Hosam Easa Elsaied \\ Genetics and Biotechnology Research Group, Department of Aquaculture, National Institute of Oceanography and \\ Fisheries, NIOF, Cairo, Egypt. \\ Accepted 8 August, 2013
}

\begin{abstract}
Culture-independent molecular approach was used to explore and evaluate the diversity of Dunaliella species living at the salt field Malahat El-Max Alexandria, Egypt. Bulk genomic DNA was extracted directly from the collected salt water samples. Specific PCR primers and methodology were designed to amplify the gene $c b b L$, which encodes the large subunit of the enzyme ribulose-1,5-bisphosphate carboxylase/oxygenase (RuBisCO, EC 4.1.1.39) of only Dunaliella species, from the extracted microbial metagenome. The 700 bp-PCR amplicons were cloned and $c b b L$ clone library was constructed and analyzed by sequencing. Rarefaction curve was saturated at sequence analyses of 23 clones, obtaining 19 phylotypes of Dunaliella $c b b L$, representing the total composition of Dunaliella in the collected sample. All recorded phylotypes had the known deduced amino acid $c b b L$ motive sequence and catalytic sites. Fingerprint sequence, characterizing Dunaliella $c b b L$, was recorded. The $c b b L$ phylotypes were grouped into two distinct phylogenetic clusters. The cluster 1 , consisting of 18 current $c b b L$ phylotypes was rooted with a cluster containing $c b b L s$ of Dunaliella salina, Dunaliella bioculata, Dunaliella primolecta and Dunaliella tertiolecta. The single phylotype, uncultured Dunaliella EIMax.3, forming cluster 2, showed a unique phylogenetic lineage in the evolution of Dunaliella cbbL. This study introduced the first functional gene markers for exploring Dunaliella species in salt waters without culture.
\end{abstract}

Key words: Uncultured Dunaliella, RuBisCO cbbL, solar saltern water, diversity.

\section{INTRODUCTION}

The genus Dunaliella, belonging to Chlorophyceae, has been represented by 27 known species, of which 23 are from salt water. Species of Dunaliella occur in freshwater, euryhaline habitats of all continents, oceans including the Dead Sea and even the salt lakes of the Antarctic (Tafreshi and Shariati, 2009). Thus, Dunaliella is a global genus of algae, thriving in habitats with wide ranges of salinity, $\mathrm{pH}$, light intensity and temperature. The characterization of economically important algae in solar salterns has become a key focus for many research groups all over the world (Chen and Jiang, 2009). Dunaliella species that are living in these fields, have an economic importance due to its highly production of antioxidants (Oren, 2010). In Egypt, there are several coastal solar salterns, where Dunaliella is living, mainly on and near to the Mediterranean coast. Studies on Dunaliella in Egyptian aquatic habitats have been focused on characterization, environmental stresses and biotechnological applications of isolated species, including Dunaliella bardawil (Adam, 1997), Dunaliella salina (Abd El-Baky 


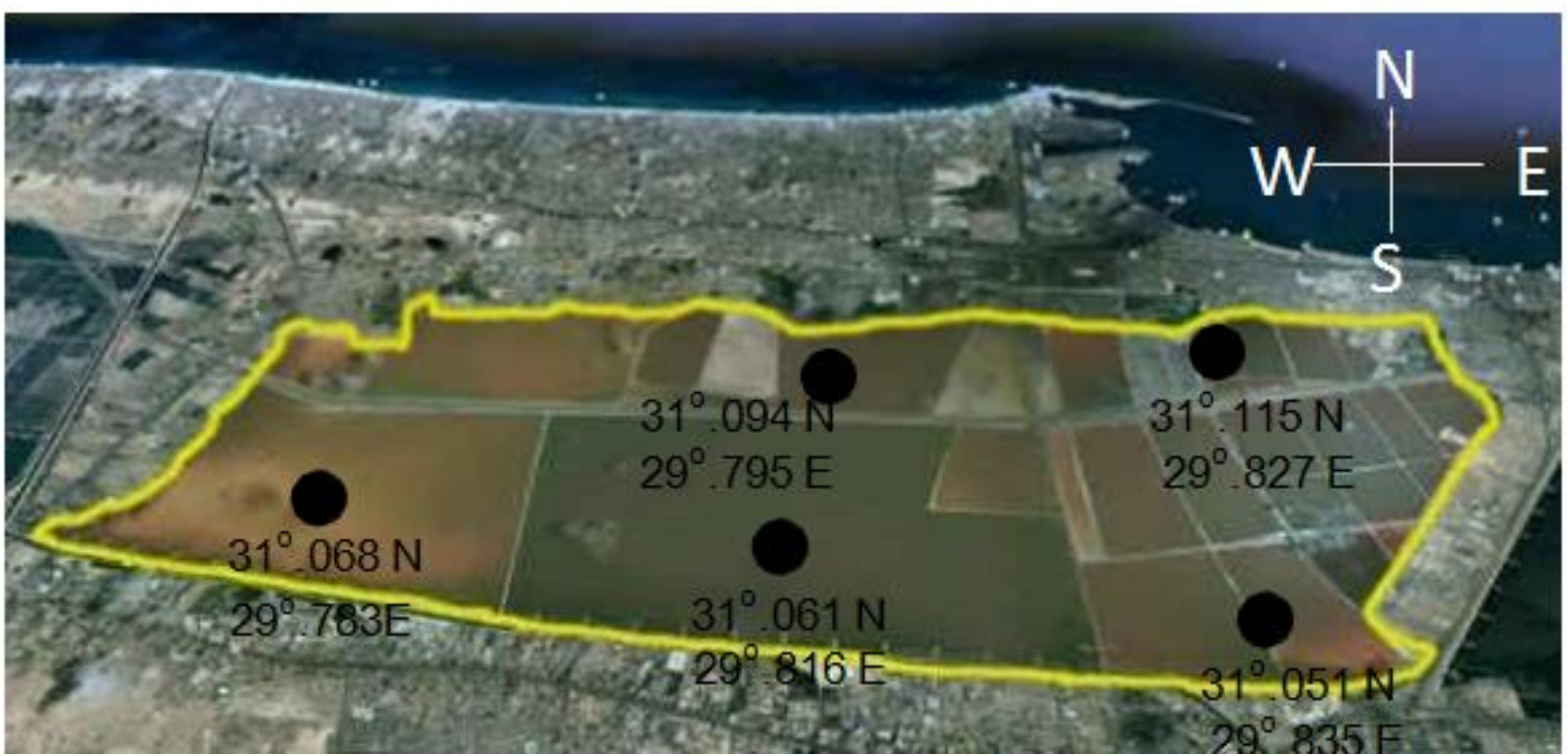

Figure 1. A map showing the sites of sampling marked by black circles.

et al., 2004; Dardir and Abd El-Tawab, 2005; Shafik, 2008), Dunaliella parva (Said, 2009) and Dunaliella tertiolecta (Tammam et al., 2011). Molecular phylogeny techniques have been applied to the taxonomic study of Dunaliella from 1999 onwards. These studies have encompassed the 18S rRNA genes and the internal transcribed spacer regions, ITS and have been based on gene sequence comparisons as well as on restriction fragment length polymorphism studies (Gomez and Gonzalez, 2001; Assunção et al., 2012). Little correlation was found between the molecular data and the traditional morphological-physiological attributes to delineate species within the genus Dunaliella (González et al., 1999, 2001).

On the basis of 18S rRNA gene sequencing, Olmos et al. (2000) could differentiate between $D$. salina, $D$. parva and $D$. bardawil as species containing one, two and three introns, respectively, within the 18S rRNA gene. Also, Hejazi et al. (2010) reported a new 18S rRNA gene arrangement in term of intron localization and nucleotide sequence in a Dunaliella isolated from Iranian salt lakes. However, molecular phylogenetic studies of Dunaliella in Egyptian solar salterns have not yet been done; remaining the diversity of Dunaliella species in these fields are poorly described. The gene, $c b b L$ that encodes the large subunit of the enzyme RuBisCO, the key of Calvin cycle has been used as an efficient molecular tool for studying the functional diversity of several phytoplankton (Tabita, 1999; Yoon et al., 2001; Ghosh and Love, 2011). The RuBisCO large subunit is distributed in almost all phytoplankton, through five different forms: form IA, IB, IC, ID and II (Watson and Tabita, 1997; John et al., 2007). The halophylic Dunaliella species, the pink micro-algae, are differentiated from other species in the class Chlorophyceae by harboring the RuBisCO form ID (Lin and Carpenter, 1997). This study developed a molecular approach for first monitoring of the diversity of Dunaliella based on PCR amplification, cloning and sequencing of the RuBisCO gene $c b b L$ in metagenomic DNA extracted from the Saltern field, Malahat El-Max, Alexandria, Egypt. Statistical analysis was applied to determine the total composition of Dunaliella $c b b L$ phylotypes and the phylogenetic tree was constructed showing the phylogenetic distribution of the recovered Dunaliella cbbL phylotypes.

\section{MATERIALS AND METHODS}

\section{Sampling}

Pink-color Dunaliella-containing surface waters, $5 \mathrm{~L}$ was collected from five stations, $1 \mathrm{~L}$ from each station, covering mostly the total area of the saltern field, Malahat El-Max, Alexandria, Egypt (Figure 1). Each liter of the collected water was filtered on a single cylindrical $0.2 \mu \mathrm{m}$ filter membrane unit (type Sterivex-GS, Millipore Corp., USA). In order to remove the trapped pink carotenoid pigments, which may link with the extracted DNA and hinder PCR amplification, the filters were washed with $10 \mathrm{ml}$ of $80 \%$ ethanol in sterile SET buffer (20\% sucrose, $50 \mathrm{mM}$ EDTA, $50 \mathrm{mM}$ Tris- $\mathrm{HCl}$, $\mathrm{pH}$ 7.6) several times. The inlet and outlet of the filters were capped, and the filters were stored at $-30^{\circ} \mathrm{C}$ until processed.

\section{Genomic DNA extraction and amplification of the Dunaliella RuBisCO gene $c b b L$}

Bulk microbial DNA, metagenome, was extracted essentially within the Sterivex-GS filters housing according to the method of Somerville et al. (1989), with modifications. Cell lysis and proteolysis were carried out within the filter housing using $5 \mathrm{M}$ guanidine 


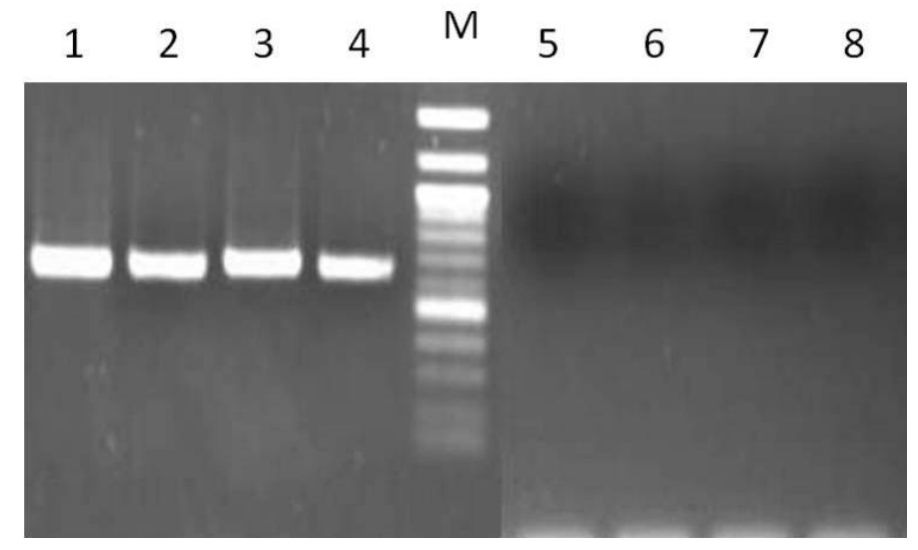

Figure 2. Efficiency of the PCR primers ID 537F and ID 1212R for amplification of RuBisCO form ID from genomes of known Dunaliella species and other phytoplankton. 1: amplification from Dunaliella bardawil strain TS-1; 2: Dunaliella bioculata CCAP 19/4; 3: Dunaliella parva IAM C-527; 4: Dunaliella salina CCAP 19/3; 5: Chlamydomonas reinhardtii; 6: Synechococcus sp. strain WH7803; 7: Rhodospirillum rubrum; 8: Chlorobium tepidum. M: 100 bp-DNA ladder marker.

thiocyanate in SET buffer at $70^{\circ} \mathrm{C}$ for 20 min with shake. Crude, which contained high-molecular-weight nucleic acids, was then drawn off the filter and purified using high pure PCR template preparation kit, Roche, Catalog no. 11796828001, Mannheim, Germany. The purified metagenomic DNAs, extracted from all samples, were combined and run on $0.9 \%$ agarose gel electrophoresis followed by staining with ethidium bromide and UV visualization. A new PCR primer set, Duna-537f (5'-RTW AAA CCT AAA TTA GGT YTA TCW GGT-3') and Duna-1212r (5'-AAT AGT ACC ACC ACC RAA TTG-3') were designed from multiple alignments of $c b b L$ sequences of Dunaliella species, incorporated to date in the DNA databases, including $D$. salina strain CCAP 19/18 (acc. no. AY531529, GQ250046), D. acidophila (HQ142901), D. bioculata (AB127991), D. primolecta strain TS-3 (AB127992), D. tertiolecta (AY882012), D. bardawil strain TS-1 (AB127990) and D. parva strain UTEX 1983 (AJ001877). The primers corresponded to positions 511 to 537 (forward primer) and 1191 to 1212 (reverse primer) of the cbbL gene of Synechococcus sp. (Shinozaki et al., 1983). PCR reaction mixture $(50 \mathrm{ml})$, contained $10 x$ EX buffer II ( $\mathrm{Mg}^{+2}$ plus), $0.2 \mu \mathrm{M}$ primer, $400 \mu \mathrm{M}$ dNTP each, 2.25U Takara EXTaq Polymerase (Takara, Japan) and 5 to $30 \mathrm{ng}$ DNA template. The PCR mixture composition was performed with an initial denaturation step of $3 \mathrm{~min}$ at $95^{\circ} \mathrm{C}$. The reaction was continued with 30 cycles of $1 \mathrm{~min}$ at $95^{\circ} \mathrm{C}, 2 \mathrm{~min}$ at $46^{\circ} \mathrm{C}$, and $3 \mathrm{~min}$ at $72^{\circ} \mathrm{C}$, with a final extension of $10 \mathrm{~min}$ at $72^{\circ} \mathrm{C}$.

PCR products had $3^{\prime}-A$ overhangs to facilitate TA-cloning into TOP10 Escherichia coli using a TOPO XL PCR-cloning kit according to the manufacturer's instructions (Catalog no. K4750-20, Invitrogen Life Technologies, Carlsbad, CA, USA). Only cells containing XL-TOPO vector with the insert were competent to grow with kanamycin. Colonies of these cells were screened directly by sequencing using vector primers T7 and an ABI 3730×I 96-capillary DNA analyzer (Applied Biosystems, Foster City, CA, USA).

\section{Sequence and bioinformatics analyses of $c b b L$ genes}

Sequencing results were introduced to FASTA (http://fasta.ddbj.nig.ac.jp/top-e.html), to determine their similarity to known Dunaliella cbbL sequences, deposited in DNA database. Nucleotide sequences for $c b b L$ open reading frames (ORFs) were submitted to Transeq, (http://www.ebi.ac.uk/emboss/transeq/), to obtain the inferred amino-acid sequences. The correct $c b b L$ ORFs were identified from the presence of diagnostic $c b b L \mathrm{CO}_{2}$ fixation motifs. Grouping of sequences into phylotypes was done based on genetic distances using the Mothur software package V.1.7.2 (Schloss et al., 2009), where cbbL sequences, having $100 \%$ deduced amino acid identities, were grouped into a single phylotype. The expected total composition of Dunaliella cbbL was determined by rarefaction analyses in the Mothur software package. The phylogenetic analysis was done based on deduced amino acid and nucleotide sequences, and included the current $c b b L$ sequences and their Dunaliella cbbL homologues, with significant homologies, $e$-value $<0.001$, from the DNA database bank. The process was performed by applying the neighbor-joining algorithm and drawing the trees using the MEGA 3.1 software (http://www.megasoftware.net/). The branching patterns of the constructed phylogenetic tree were confirmed by reconstruction of the phylogenies using two other methods of analysis, namely maximum parsimony and maximum-likelihood, contained within the Phylip package.

The sequences of recovered Dunaliella $c b b L$ were deposited in DNA data base bank under accession numbers from AB781569 to AB781587.

\section{RESULTS AND DISCUSSION}

\section{Efficiency of primers for PCR amplification of Dunaliella cbbL}

This work aimed to cover the molecular diversity of almost all Dunaliella species in the collected saline water sample. In order to achieve this target, several considerations were involved in the design of an efficient primer set for amplification of Dunaliella cbbL. The primers must be designed from $c b b L$ region, which encodes $\mathrm{CO}_{2}$ catalytic site of Dunaliella RuBisCO form ID. Hence, the codon region of the $c b b L$ catalytic site amino acid group $T(V)$ KPKLG (Newman and Gutteridge, 1993) represented specific sequence for the design of the primer Duna-537f. The primer Duna-1212r was designed from the codons that encode the catalytic amino acids QFGGGTI, characterizing the Dunaliella RuBisCO ID cbbL. These primer sequences were differed from other $c b b L$ sequences, located in other autotrophic algae, in several nucleotides, sufficient to make each of the primers binds only with Dunaliella cbbL. This was clear in the positive PCR amplifications of Dunaliella $c b b L$, while negative amplifications were noticed for $c b b L$ from other phytoplankton species (Figure 2). These primer sets provided $c b b L$ product size, $700 \mathrm{bp}$, longer than that produced by Paul et al. (2000). This gave an extended view to screen the diversity of Dunaliella cbbL.

In order to reduce the possibility of bias in amplification of Dunaliella cbbL, the PCR was tested using a range from 26 to 30 cycles, and then the amplicons were combined for cloning (Suzuki and Giovannoni, 1996). This was clear in the rarefaction curves, for the recovered Dunaliella $c b b L$, which showed saturation after analysis of 23 clones, yielding 19 phylotypes (Supplementary 


Uncultured Dunaliella ElMax-1
Uncultured Dunaliella ElMax-2
Uncultured Dunaliella ElMax-3
Uncultured Dunaliella ElMax-4
Uncultured Dunaliella ElMax-5
Uncultured Dunaliella ElMax-6
Uncultured Dunaliella ElMax-7
Uncultured Dunaliella ElMax-8
Uncultured Dunaliella ElMax-9
Uncultured Dunaliella ElMax-10
Uncultured Dunaliella ElMax-11
Uncultured Dunaliella ElMax-12
Uncultured Dunaliella ElMax-13
Uncultured Dunaliella ElMax-14
Uncultured Dunaliella ElMax-15
Uncultured Dunaliella ElMax-16
Uncultured Dunaliella ElMax-17
Uncultured Dunaliella ElMax-18
Uncultured Dunaliella ElMax-19
Dunaliella bioculata
Dunaliella primolecta
Dunaliella tertiolecta
Dunaliella bardawil
Dunaliella salina
Dunaliella parva
Chlamydomonas reinhardti
Synechococcus sp.
Rhodospirillum rubrum

Figure 3. Multiple alignments, within the amplification size, $700 \mathrm{bp}$, of recorded uncultured Dunaliella EIMax.1 to 19 , and $c b b L s$ from other known phytoplankton recorded in database. The nucleotide alignments are only in the sites of RuBisCO cbbL motive sequence, marked by shading, and catalytic amino acids, bold face. Alignments in the box represent the finger print sequence of Dunaliella cbbL. Species used in the alignments had accession numbers listed in Figure 4.

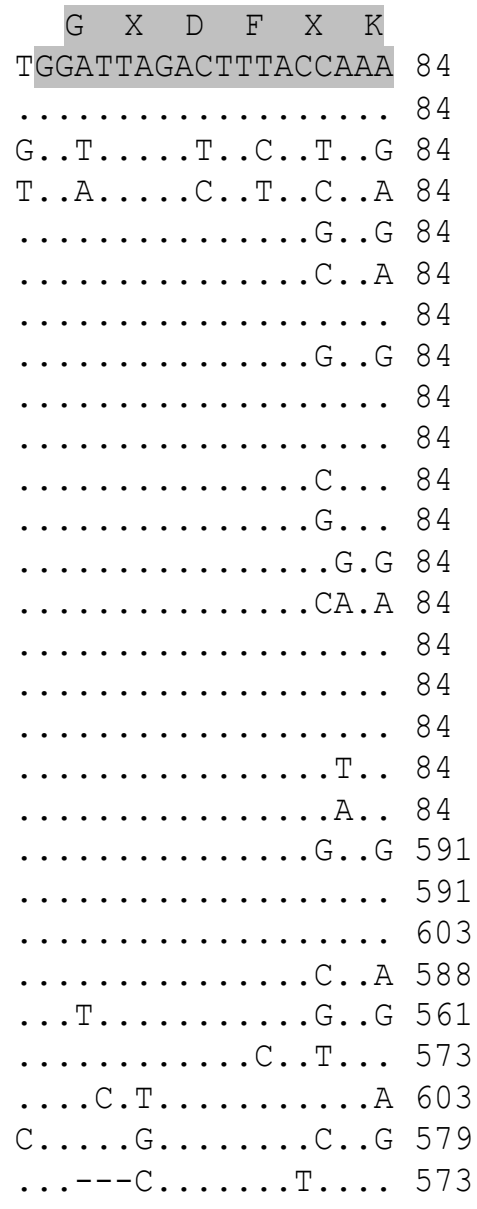

GTAAAACCTAAATTAGGTTTATCTGGT 27

$\ldots \ldots \ldots \ldots \ldots \ldots \ldots \ldots \ldots$

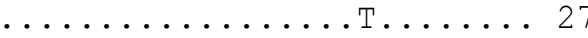

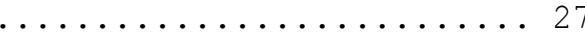

$\ldots \ldots \ldots \ldots \ldots \ldots \ldots \ldots \ldots \ldots$

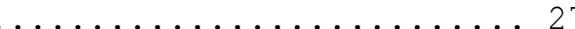

$\ldots \ldots \ldots \ldots . \ldots \ldots \ldots$

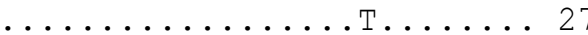

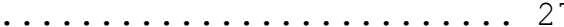

$\ldots \ldots \ldots \ldots \ldots \ldots$

$\ldots \ldots \ldots \ldots \ldots \ldots \ldots \ldots \ldots$

$\ldots \ldots \ldots \ldots$

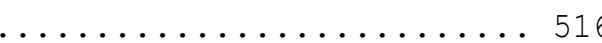

................... 546

....G..G......C.GAGC..C 522

$\ldots \ldots \ldots \ldots \ldots$ TCCC 519 


Uncultured Dunaliella ElMax-1
Uncultured Dunaliella ElMax-2
Uncultured Dunaliella ElMax-3
Uncultured Dunaliella ElMax-4
Uncultured Dunaliella ElMax-5
Uncultured Dunaliella ElMax-6
Uncultured Dunaliella ElMax-7
Uncultured Dunaliella ElMax-8
Uncultured Dunaliella ElMax-9
Uncultured Dunaliella ElMax-10
Uncultured Dunaliella ElMax-11
Uncultured Dunaliella ElMax-12
Uncultured Dunaliella ElMax-13
Uncultured Dunaliella ElMax-14
Uncultured Dunaliella ElMax-15
Uncultured Dunaliella ElMax-16
Uncultured Dunaliella ElMax-17
Uncultured Dunaliella ElMax-18
Uncultured Dunaliella ElMax-19
D. bioculata
D. primolecta
D. tertiolecta
D. bardawil
D. salina
D. parva
C. reinhardtii
Synechococcus sp.
R. rubrum

\begin{tabular}{|c|c|c|c|c|c|}
\hline K & & $\mathbf{G}$ & & $\mathbf{G}$ & \\
\hline AAA & 483 & TCTGGTGGT & 624 & GGTGGT & 693 \\
\hline .. & 483 & $\ldots \ldots \ldots$ & 624 & $\ldots \ldots$ & 693 \\
\hline & 483 & $\ldots \ldots \ldots$ & 624 & $\ldots \ldots$ & 693 \\
\hline & 483 & $\ldots \ldots \ldots$ & 624 & $\ldots \ldots$ & \\
\hline & 483 & $\ldots \ldots \ldots$ & 624 & $\ldots \ldots$ & \\
\hline & 483 & $\ldots \ldots \ldots$ & 624 & $\ldots \ldots$ & \\
\hline & 483 & $\ldots \ldots \ldots$ & 624 & $\ldots \ldots$ & \\
\hline & 483 & $\ldots \ldots \ldots$ & 624 & $\ldots \ldots$ & \\
\hline & 483 & $\ldots \ldots \ldots$ & 624 & $\ldots \ldots$ & \\
\hline & 483 & $\ldots \ldots \ldots$ & 624 & $\ldots \ldots$ & \\
\hline & 4 & $\ldots \ldots \ldots$ & 24 & $\ldots \ldots$ & \\
\hline & 483 & $\ldots \ldots \ldots$ & 624 & $\ldots \ldots$ & \\
\hline & & $\ldots \ldots \ldots$ & 624 & $\ldots \ldots$ & \\
\hline & 483 & $\ldots \ldots \ldots$ & 624 & $\ldots \ldots$ & \\
\hline & 4 & $\ldots \ldots \ldots$ & 624 & $\ldots \ldots$ & \\
\hline & 483 & $\ldots \ldots \ldots$ & 624 & & \\
\hline & 483 & $\ldots \ldots \ldots$ & 624 & $\ldots \ldots$ & \\
\hline & & $\ldots \ldots \ldots$ & 624 & $\ldots \ldots$ & \\
\hline & 483 & $\ldots \ldots$ & 624 & $\cdots$ & \\
\hline & 990 & $\cdots \cdots \cdots$ & 1131 & & \\
\hline & 990 & $\ldots$. & 1131 & & \\
\hline & 1002 & $\ldots \ldots \ldots$ & 1143 & & \\
\hline & 987 & $\ldots \ldots$ & 1128 & & \\
\hline & 960 & $\ldots \ldots \ldots$ & 1101 & $\ldots \ldots$ & \\
\hline & 972 & $\ldots \ldots \ldots$ & 1111 & ------ & \\
\hline & 1002 & $\cdots A \ldots C \ldots$ & 1143 & & \\
\hline & 978 & $\ldots$ C.... & 19 & & \\
\hline & 980 & $A G \ldots \ldots C$ & 1110 & . C . C & \\
\hline
\end{tabular}

Figure 3. Contd.

GCTGAAGGAATGCTTCAACGTGCACAA-3', of the Dunaliella cbbL (Figure 3). Consequently, the amino acids AGLQQ (Figure 3), encoded by this finger print nucleotide sequence, were considered as Dunaliella RuBisCO key amino acids, which differentiate it from those of in other phytoplankton. $c b b L$ finger print sequences have been recorded for several autotrophic bacterial endosymbionts and used as nucleotide probes for in situ localization of the corresponding $\mathrm{cbbL}$ gene in the host tissues (Elsaied et al., 2002, 2006; Kimura et al., 2003).

On the other hand, red-like RuBisCO $c b b L$ marker sequence has been used as a TaqMan probe for detection and quantification of soil autotrophic bacteria (Selesi et al., 2007). Hence, this current Dunaliella cbbL finger print sequence may be used as a biomarker for detection of uncultured Dunaliella by probing and hybridization techniques.

\section{The recovered Dunaliella $c b b L$ phylotypes were phylogenetically unique}

Phylogenetic tree of $c b b L$ was constructed in order to demonstrate the classification of the recovered Dunaliella $c b b L$ (Figure 4). The nineteen $c b b L$ phylotypes were distributed in two unique phylogenetic clusters. The cluster 1 harbored $18 \mathrm{cbbl}$ phylotypes, which showed an average value of $95 \%$ ND (nucleotide identity), that is, $97 \%_{a a}$ (amino acid identity) with each others. On the other hand, the $c b b L$ phylotypes, constituting cluster 1 , were distinct from other known Dunaliella species located in the same Dunaliella phylogenetic branch by showing homologies of 89 to $90 \%$ ND (92 to 93\% aa) (Figure 4). The uncultured Dunaliella EIMax.3, forming the cluster 2, had a unique $c b b L$ phylogenetic lineage. It showed average identity of $87 \%$ ND $(89 \%$ aa $)$ with other current Dunaliella 


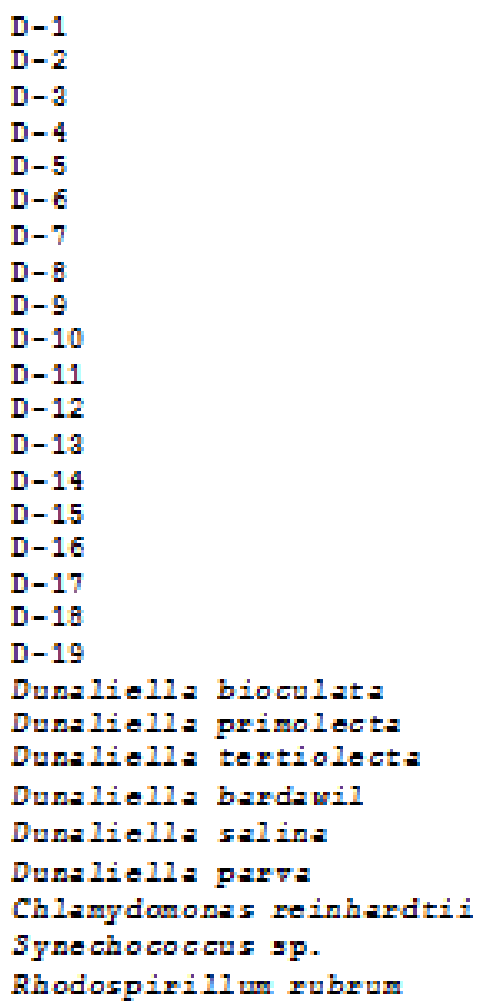

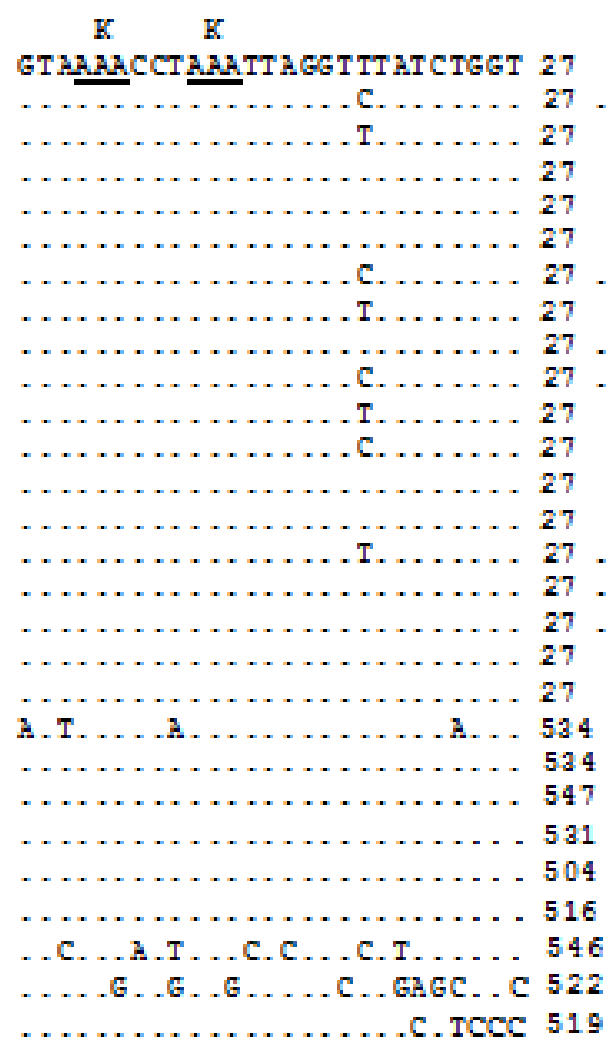

$\begin{array}{llllll}G & X & D & F & X & R\end{array}$

TGGATTAGACTTTACCAAA B4

G..T....T.C.T.G 84

T.......C. .T.C... 84

.........6.6.64

............ 84

$\ldots \ldots \ldots \ldots B^{8}$

..........6.6.68

$\ldots \ldots \ldots \ldots \ldots B^{84}$

$\ldots \ldots \ldots \ldots .68^{8}$

.............. 84

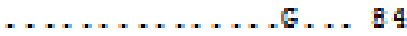

..........6.6.64

….......... 84

$\ldots \ldots \ldots \ldots \ldots$ B

$\ldots \ldots \ldots \ldots B^{8}$

$\ldots \ldots \ldots \ldots \ldots \ldots B^{8}$

$\ldots \ldots \ldots$. $\ldots$ T 4

.............. 84

...........6.6 591

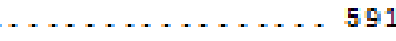

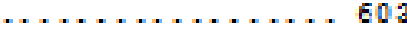

$\ldots \ldots \ldots$............ 586

..T........6.6.6561

............. 573

............... 603

c...6.........6.6 579

...-C.......... 573

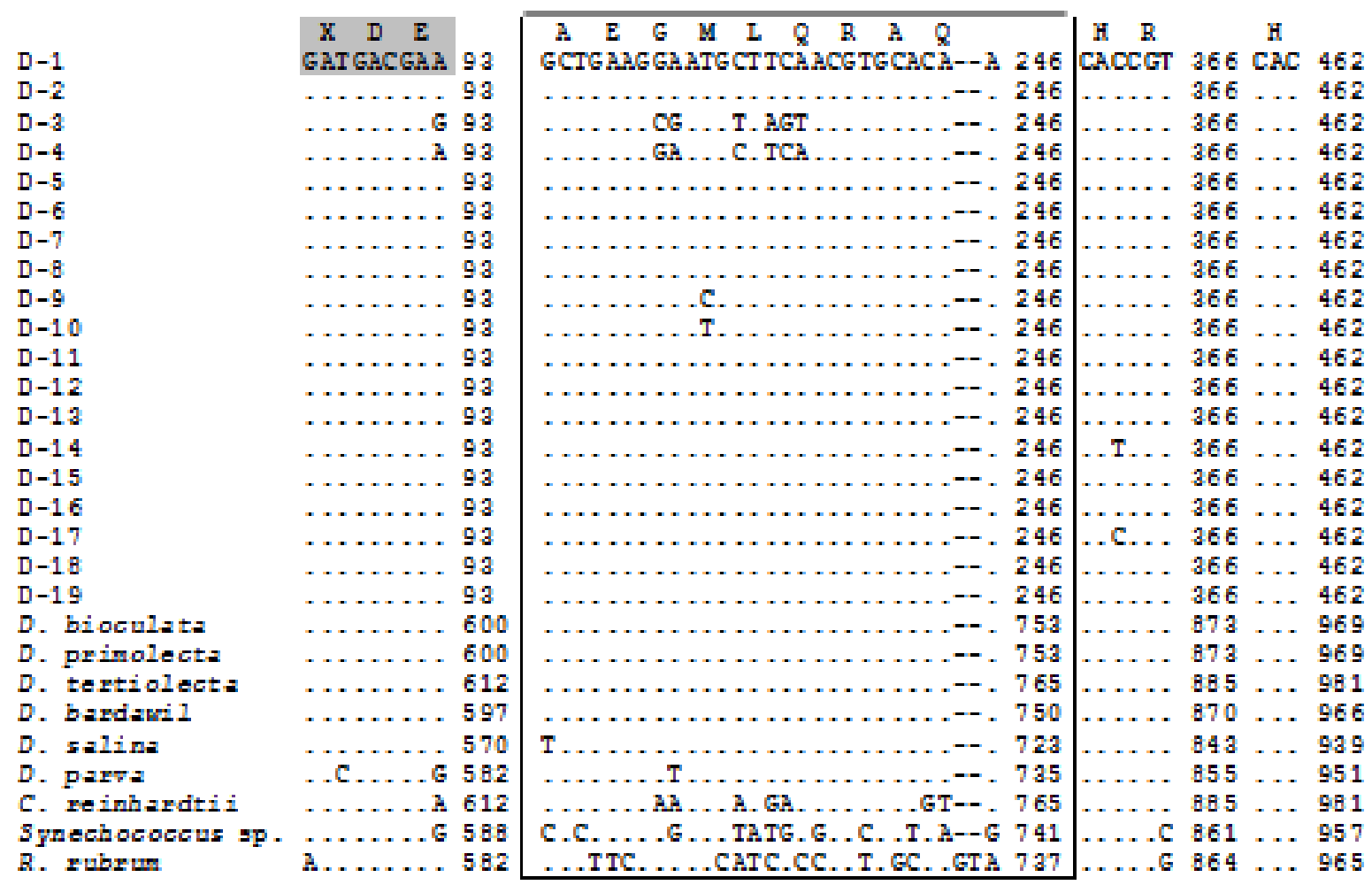

Figure 4. A tree shows the phylogenetic relationship between the current uncultured Dunaliella clones, EIMax.1 to 19 , marked with bold face, and other $c b b L$ sequences from Dunaliella species available in database, beside $c b b L$ sequences from other phytoplankton, as out groups. The consensus tree was constructed by neighbour-joining analysis and confirmed by maximum-parsimony and maximum-likelihood methods. Bootstrap values of $>50 \%$ are indicated at the nodes. The bar represents 0.1 changes per amino acid or nucleotide. 


\begin{tabular}{|c|c|c|c|c|c|c|}
\hline & $\mathbf{K}$ & & G & & & \\
\hline $\mathrm{D}-1$ & $A A A$ & 483 & TCTGGTGGT & 624 & GGTGGT & 693 \\
\hline$D-2$ & $\ldots$ & 483 & $\ldots \ldots \ldots$ & 624 & $\ldots \ldots$ & 693 \\
\hline$D-3$ & $\ldots$ & 483 & $\ldots \ldots \ldots$ & 624 & $\ldots \ldots$ & 693 \\
\hline$D-4$ & $\ldots$ & 483 & $\ldots \ldots \ldots$ & 624 & $\ldots \ldots$ & 693 \\
\hline$D-5$ & $\ldots$ & 483 & $\ldots \ldots \ldots$ & 624 & $\ldots \ldots$ & 693 \\
\hline$D-6$ & $\ldots$ & 483 & $\ldots \ldots \ldots$ & 624 & $\ldots \ldots$ & 693 \\
\hline$D-7$ & $\ldots$ & 483 & $\ldots \ldots \ldots$ & 624 & $\ldots \ldots$ & 693 \\
\hline$D-8$ & $\ldots$ & 483 & $\ldots \ldots \ldots$ & 624 & $\ldots \ldots$ & 693 \\
\hline$D-9$ & $\ldots$ & 483 & $\ldots \ldots \ldots$ & 624 & $\ldots \ldots$ & 693 \\
\hline$D-10$ & $\ldots$ & 483 & $\ldots \ldots \ldots$ & 624 & $\ldots \ldots$ & 693 \\
\hline$D-11$ & $\ldots$ & 483 & $\ldots \ldots \ldots$ & 624 & $\ldots \ldots$ & 693 \\
\hline$D-12$ & $\ldots$ & 483 & $\ldots \ldots \ldots$ & 624 & $\ldots \ldots$ & 693 \\
\hline$D-13$ & $\ldots$ & 483 & $\ldots \ldots$ & 624 & $\ldots$ & 693 \\
\hline$D-14$ & $\ldots$ & 483 & $\ldots$ & 624 & $\ldots$ & 693 \\
\hline$D-15$ & $\ldots$ & 483 & $\ldots \ldots \ldots$ & 624 & $\ldots \ldots$ & 693 \\
\hline$D-16$ & $\ldots$ & 483 & $\ldots \ldots \ldots$ & 624 & $\ldots \ldots$ & 693 \\
\hline$D-17$ & $\ldots$ & 483 & $\ldots \ldots \ldots$ & 624 & $\ldots$ & 693 \\
\hline$D-18$ & $\ldots$ & 483 & $\ldots$ & 624 & $\ldots$ & 693 \\
\hline $\mathrm{D}-19$ & $\ldots$ & 483 & . . & 624 & .. & 693 \\
\hline D. bioculata & $\ldots$ & 990 & . . & 1131 & . . & 1200 \\
\hline D. primolecta & $\ldots$ & 990 & $\ldots \ldots \ldots$ & 1131 & $\ldots$ & 1200 \\
\hline D. tertiolecta & $\ldots$ & 1002 & $\ldots \ldots \ldots$ & 1143 & . & 1212 \\
\hline D. bardawil & $\ldots$ & 987 & $\ldots \ldots \ldots$ & 1128 & $\ldots$ & 1197 \\
\hline D. salina & . . & 960 & & 1101 & & 1170 \\
\hline D. parva & $\ldots$ & 972 & & 1111 & ------ & \\
\hline C. reinhardtii & $\ldots$ & 1002 & . A..C... & 1143 & $\ldots \ldots$ & 1212 \\
\hline Synechococcus sp. & $\ldots G$ & 978 & $\ldots$. . ... & 1119 & & 1189 \\
\hline R. rubrum & $\ldots$ & 980 & $A G \ldots \ldots C$ & 1110 & $\ldots \mathrm{C} \ldots \mathrm{C}$ & 1182 \\
\hline
\end{tabular}

Figure 4. Contd.

cbbL phylotypes and those of known Dunaliella species.

These results may indicate that dynamically studied solar saltern field may select for different and diverse uncultured Dunaliella lineages, which added to Dunaliella phylogeny. In conclusion, this study could monitor uncultured Dunaliella based on specific cbbL-PCR approach. This strategy will help in finding diverse Dunaliella species yet to be discovered and open a new window to study the phylogeny of uncultured Dunaliella in aquatic environments.

\section{ACKNOWLEDGEMENTS}

We wish to express our deep gratitude to Dr. Akihiko Maruyama, National Institute of Advanced Industrial Science and Technology, AIST, Tsukuba Science city, Japan, for providing the genomes of Dunaliella species. This research was supported by the Grant in-Aid for Scientific Research, National Institute of Oceanography, Egypt.

\section{REFERENCES}

Abd El-Baky H, El Baz F, El-Baroty G (2004). Production of Antioxidant by the Green Alga Dunaliella salina. Int. J. Agric. Biol. 6: 49-57.

Adam MS (1997). Metabolic response of the halotolerant green alga Dunaliella bardawil to nitrogen: Phosphorus ratios in batch culture. Folia Microbiol. 42: 357-360.

Assunção $P$, Jaén-Molina R, Caujapé-Castells J, de la Jara A, Carmona L, Freijanes K, Mendoza H (2012). Molecular taxonomy of Dunaliella (Chlorophyceae), with a special focus on $D$. salina: ITS2 sequences revisited with an extensive geographical sampling. Aquat. Biosyst. 8: 2.

Chen H, Jiang JG (2009). Osmotic responses of Dunaliella to the changes of salinity. J. Cell Physiol. 219: 251-258.

Dardir AA, Abd EL-Tawab A (2005). Usage lake quaroun water to cultivation of Dunaliella Salina as biotechnology in Fayoum, Egypt. Egypt J. Aquat. Res. 31: 341-351.

Elsaied H, Kaneko R, Naganuma T (2006). Molecular Characterization of a deep-Sea methanotrophic mussel symbiont that carries a RuBisCO gene. Mar. Biotechnol. 8: 511-520.

Elsaied H, Kimura H, Naganuma T (2002). Molecular characterization and endosymbiotic localization of the gene encoding ribulose-1,5bisphosphate carboxylase/oxygenase (RuBisCO) form II in the deepsea vestimentiferan trophosome. Microbiology 148: 1947-1957.

Ghosh S, Love N (2011). Application of $r b c L$ based molecular diversity analysis to algae in wastewater treatment plants. Bioresour. Technol. 
102: 3619-3622.

Gomez PI, Gonzalez MA (2001). Genetic polymorphism in eight Chilean strains of the carotenogenic microalga Dunaliella salina Teodoresco (Chlorophyta). Biol. Res. 34: 23-30.

González MA, Coleman AW, Gómez PI, Montoya R (2001). Phylogenetic relationship among various strains of $D$ u $\mathrm{n}$ a li e I la (Chlorophyceae) based on nuclear ITS rDNA sequences. J. Phycol. 37: 604-611.

González MA, Gómez PI, Montoya R (1999). Comparison of PCR-RFLP analysis of the ITS region with morphological criteria of various strains of $D$ u $n$ a / ie / / a. J. Appl. Phycol. 10: 573-580.

Guo X, Yin H, Cong J, Dai Z, Liang Y, Liu X (2013). RubisCO gene clusters found in a metagenome microarray from acid mine drainage. Appl. Environ. Microb. 79: 2019-2026.

Hejazi MA, Barzegari A, Gharajeh NH, Hejazi MS (2010). Introduction of a novel 18S rDNA gene arrangement along with distinct ITS region in the saline water microalga Dunaliella. Saline Systems 6:4.

John DE, Wang ZA, Liu X, Byrne RH, Corredor JE, López JM, Cabrera A, Bronk DA, Tabita FR, Paul JH (2007). Phytoplankton carbon fixation gene (RuBisCO) transcripts and air-sea CO2 flux in the Mississippi River plume. ISME J. 1: 517-531.

Kimura H, Sato M, Sasayama Y, Naganuma T (2003). Molecular characterization and in situ localization of endosymbiotic 16S Ribosomal RNA and RuBisCO genes in the pogonophoran tissue. Mar. Biotechnol. 5: 261-269.

Lin S, Carpenter, E (1997). Rubisco of Dunaliella tertiolecta is redistributed between the pyrenoid and the stroma as a light /shade response. Mar. Biol. 127: 521-529.

Newman J, Gutteridge S (1993). The X-ray structure of Synechococcus PCC6301 ribulose-bisphosphate carboxylase/oxygenase-activated quaternary complex at 2.2- $\mathrm{A}^{\circ}$ resolution. J. Biol. Chem. 268: 2587625886.

Olmos J, Paniagua J, Contreras R (2000). Molecular identification of Dunaliella sp. utilizing the 18S rDNA gene. Lett. Appl. Microbiol. 30:8084.

Oren A (2010). Industrial and environmental applications of halophilic microorganisms. Environ. Technol. 31: 825-834.

Paul JH, Alfreider A, Wawrik B (2000). Micro- and macrodiversity in rbcL sequences in ambient phytoplankton populations from the southeastern Gulf of Mexico. Mar. Ecol. Prog. 198: 9-18.
Said HA (2009). Changes in levels of cellular constituents of Dunaliella parva associated with inorganic phosphate depletion. Middle East J. Sci. Res. 4: 94-99.

Schloss PD, Westcott SL, Ryabin T, Hall JR, Hartmann M, Hollister EB et al. (2009). Introducing Mothur: open source, platform-independent, community-supported software for describing and comparing microbial communities. Appl. Environ. Microb. 75: 7537-7541

Selesi D, Pattis I, Schmid M, Kandeler E, Hartmann, A (2007). Quantification of bacterial RubisCO genes in soils by cbbL targeted real-time PCR. J. Microbiol. Methods 69: 497-503.

Shafik M (2008). Phytoremediation of some heavy metals by Dunaliella salina. Glob. J. Environ. Res. 2: 01-11.

Shinozaki K, Yamada C, Takahata N, Sugiura M (1983). Molecular cloning and sequence analysis of the cyanobacterial gene for the large subunit of ribulose-1,5-bisphosphate carboxylase/oxygenase. Proc. Natl. Acad. Sci. USA 80: 4050-4054.

Somerville C, Knight IT, Straube WL, Colwell R (1989). Simple, rapid method for direct isolation of nucleic acids from aquatic environments. Appl. Environ. Microb. 55: 548-554.

Suzuki M, Giovannoni S (1996). Bias caused by template annealing in the amplification of mixtures of 16S rRNA genes by PCR. Appl. Environ. Microb. 62: 625-630.

Tabita F (1999). Microbial ribulose 1,5-bisphosphate carboxylase/ oxygenase: a different perspective. Photosyn. Res. 60: 1-28.

Tafreshi A, Shariati M (2009). Dunaliella biotechnology: methods and applications. J. Appl. Microb. 107: 14-35.

Tammam A, Fakhry E, El-Sheekh M (2011). Effect of salt stress on antioxidant system and the metabolism of the reactive oxygen species in Dunaliella salina and Dunaliella tertiolecta. Afr. J. Biotechnol. 10: 3795-3808.

Watson G, Tabita F (1997). Microbial ribulose 1,5-bisphosphate carboxylase/oxygenase: a molecule for phylogenetic and enzymelogical investigation. FEMS Microbiol. Lett. 146: 13-22.

Yoon HS, Lee J , Boo S, Bhattacharya D (2001). Phylogeny of Alariaceae, Laminariaceae, and Lessoniaceae (Phaeophyceae) based on plastid-encoded RuBisCO spacer and nuclear-Encoded ITS sequence comparisons. Mol. Phylo. Evol. 21: 231-243. 


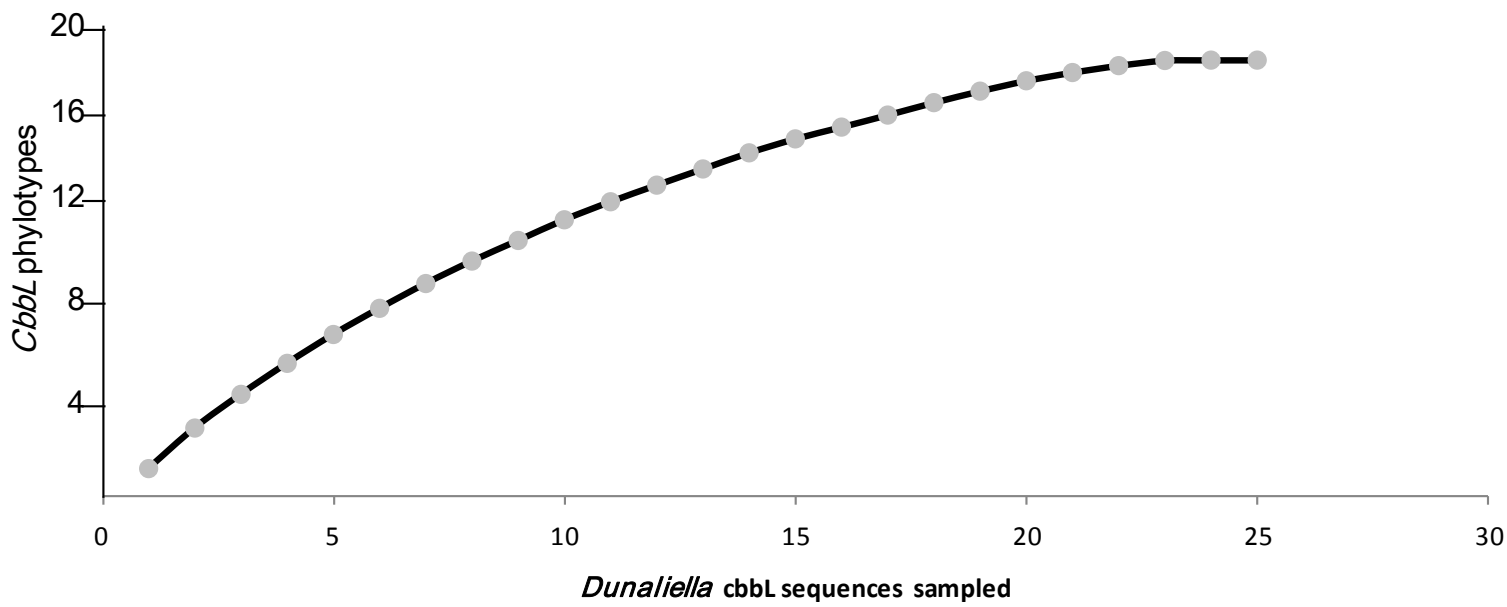

Supplementary Figure 1. Rarefaction curves for the expected number of Dunaliella $c b b L$ gene phylotypes. 